\title{
ANALISIS FITOKIMIA, TOKSISITAS DAN ANTIOKSIDAN EKSTRAK SERBUK SARI (Bee pollen) LEBAH Trigona spp.
}

\author{
Syafrizal, Nova Hariani, dan Budiman \\ Jurusan Biologi, Fakultas MIPA, Universitas Mulawarman \\ Jalan Barong Tongkok No. 4 Kampus Gunung Kelua Samarinda, Kalimantan Timur \\ Email Korespondensi : syafrizalfachmy@gmail.com
}

\begin{abstract}
Phytochemical analysis, toxicity test, the antioxidant activity and secondary metabolites of bee pollen a hive products Trigona spp. has been investigated. Bee pollen samples extracted with ethanol by masseration method with using a rotary evaporator. Ethanol obtained crude extract was fractionated by ethanol and ethyl acetate. Secondary metabolites of bee pollen with phytochemical analysis showed that the ethanol extract contains alkaloids and phenolic rough. The ethanol extract fraction containing alkaloids. Ethyl acetate extract fractions contain alkaloids and phenolic. In a test toxicity of an increase in mortality of larvae shrimp (Artemia salina L.) and then processed using SAS Probit Analysis to determine the lethal concentration 50\% (Lc50). The results were obtained data shows that the most active fractions is extract ethanol with value is 249.6079 ppm. Test results of antioxidant activity by DPPH method using spectrophotometry showed that $50 \%$ inhibitory concentration (Ic50) is obtained in the crude extract was $104.84 \mathrm{ppm}$ Ethanol, ethanol fraction value is $172.67 \mathrm{ppm}, 75.99 \mathrm{ppm}$ of ethyl acetate fraction and vitamin $\mathrm{C}$ is $10.79 \mathrm{ppm}$, this suggests that the most active fraction is ethyl acetate with Ic50 is $75.99 \mathrm{ppm}$.
\end{abstract}

Keywords: Bee pollen, phytochemical analysis, toxicity, antioxidant activity, DPPH method.

\begin{abstract}
ABSTRAK
Analisa fitokimia, uji toksisitas, aktivitas antioksidan dan metabolit sekunder dari serbuk sari (bee pollen) produk sarang Trigona spp. telah diteliti. Sampel serbuk sari di ekstrak dengan metode masseration menggunakan rotary evaporator dengan pelarut etanol. Ekstrak kasar Etanol yang diperoleh difraksinasi dengan pelarut etanol dan etil asetat. Hasil analisa fitokimia Metabolit sekunder menunjukkan bahwa ekstrak etanol kasar mengandung alkaloid dan fenolik. Fraksi Ekstrak etanol mengandung alkaloid, sedangkan fraksi ekstrak Etil asetat mengandung alkaloid dan fenolik. Pada uji toksisitas bee pollen dengan menggunakan larva udang (Artemia salina L.) yang kemudian diolah menggunakan Analisis Probit SAS dalam menentukan nilai konsentrasi letal 50\% ( $\left.\operatorname{Lc}_{50}\right)$. Hasil uji menunjukkan bahwa fraksi yang paling aktif adalah ekstrak etanol, dengan nilai $\mathrm{LC}_{50}$ adalah 249,6079 ppm. Hasil pengujian aktivitas antioksidan dengan metode DPPH menggunakan spektrofotometri, diketahui bahwa konsentrasi penghambatan $50 \%$ (IC 50 ) pada ekstrak kasar Etanol adalah 104,84 ppm, pada fraksi etanol sebesar 172,67 ppm, pada fraksi etil asetat adalah 75,99 ppm, sedangkan nilai pada vitamin $C$ adalah 10,79 ppm, ini menunjukkan bahwa fraksi yang paling aktif adalah etil asetat dengan nilai $\mathrm{IC}_{50}$ pada kisaran 75,99 ppm.
\end{abstract}

Kata kunci: Bee pollen, fitokimia, toksisitas, antioksidan, metode DPPH. 


\title{
PENDAHULUAN
}

Kesehatan merupakan suatu kondisi penting pada tubuh manusia, oleh karena itu untuk menjaganya diperlukan asupan yang bermanfaat bagi tubuh. Satu dari sekian banyak asupan makan yang bermanfaat, yang banyak dikonsumsi oleh masyarakat guna menjaga kesehatan tubuhnya adalah makanan yang berasal dari produk sarang lebah. Sarang lebah madu, selain menghasilkan Madu, Royal Jelly dan Propolis, juga memproduksi serbuk sari (Bee pollen) yang memiliki khasiat bagi kesehatan tubuh manusia.

Bee pollen mengandung bahan kimia alami dengan komposisi yang kompleks, bee pollen mempunyai khasiat yang bermacam-macam, di antaranya adalah sebagai antioksidan. Kekuatan optimum serta daya tahan tubuh terhadap berbagai penyakit bisa diperoleh dengan menambahkan $20 \%$ bee pollen pada makanan kita. Bee pollen dengan kelengkapan unsur gizinya, bekerja terutama pada sel-sel metabolisme (Faegri, 1989). Berdasarkan penelitian sebelumnya, dalam analisis fitokimia ekstrak etanol bee pollen, positif mengandung senyawa flavonoid dan fenolik (Sholikhah, 2012). namun belum ada penelitian mendalam secara kimia tentang kandungan kimia bee pollen dan juga untuk pemanfaatan ekstrak bee pollen sebagai obat alternatif yang aman sehingga perlu ditentukan tingkat toksisitasnya.

Berdasarkan uraian di atas, perlu dilakukan penelitian untuk mengetahui jenis senyawa metabolit sekunder, fraksi apa yang paling aktif terhadap larva udang (Artemia salina L.) melalui uji Brine Shrimp Lethality Test (BSLT), untuk menentukan efektivitas daya racun dari setiap fraksi (Meyer dkk., 1982) serta untuk mengetahui besarnya aktivitas antioksidan dengan metode perendaman radikal 2,2-diphenyl-1-picrylhidrazyl (DPPH) dari ekstrak serbuk sari (bee pollen).

\section{METODE PENELITIAN}

\section{Bahan}

Bahan-bahan yang digunakan adalah bee pollen, etanol, etil asetat, kloroform, heksana, dietil eter, $\mathrm{H}_{2} \mathrm{SO}_{4} 2 \mathrm{M}$, asam asetat glasial, $\mathrm{Bi}\left(\mathrm{NO}_{3}\right)_{3} .5 \mathrm{H}_{2} \mathrm{O}, \mathrm{HgCl}_{2}, \mathrm{HNO}_{3}$ pekat, $\mathrm{KI}, \mathrm{FeCl}_{3}, \mathrm{HCl}$, serbuk $\mathrm{Mg}$, aquades, air laut, DMSO, DPPH (2,2-diphenyl-1picrylhidrazyl) dan Vitamin C.

\begin{abstract}
Alat
Peralatan yang digunakan dalam penelitian ini adalah rotari evaporator, beaker gelas, erlenmeyer, gelas ukur, corong, corong pisah, neraca analitik, tabung reaksi, pipet volume, pipet tetes, mikropipet ukuran 100-1000 $\mu \mathrm{L}$, labu ukur, batang pengaduk, kertas saring Whatman no.1, aluminium foil, lampu TL, hot plate, freezer dan spektrofotometer UV-Vis.
\end{abstract}

\section{Prosedur Penelitian}

Sampel serbuk sari (Bee pollen) yang telah dikering anginkan ditimbang, kemudian dimaserasi dengan etanol, diekstraksi sampai larutan ekstrak tidak berwarna lagi. Kemudian disaring dan pelarut diuapkan dengan rotari evaporator sehingga diperoleh ekstrak kasar etanol. Selanjutnya ekstrak kasar etanol tersebut difraksinasi menggunakan pelarut dengan perbedaan kepolaran pelarut. Caranya adalah sebagai berikut: ekstrak kasar etanol yang telah bebas etanol ditambahkan campuran etanol dan etil asetat dengan perbandingan 1:2 ( $\mathrm{v} / \mathrm{v})$. Fraksinasi dilakukan dengan corong pisah, sehingga diperoleh 2 fraksi, yaitu fraksi etanol dan fraksi etil asetat. Fraksi etil asetat dipekatkan dengan rotari evaporator dan disebut sebagai ekstrak fraksi etil asetat. Fraksi etanol dipekatkan dengan rotari evaporator dan disebut sebagai ekstrak fraksi etanol. Pada ekstrak kasar dan kedua fraksi (fraksi etil asetat dan fraksi etanol) kemudian dilakukan uji fitokimia dan uji 
mortalitas larva udang (brine shrimp lethality test). Selanjutnya ekstrak kasar dan kedua fraksi dilakukan uji aktivitas antioksidan dengan menggunakan metode peredaman radikal bebas 2,2-diphenyl-1-picrylhidrazyl (DPPH) dengan menggunakan spektrofotometer.

\section{HASIL DAN PEMBAHASAN}

Sampel yang digunakan dalam penelitian ini adalah serbuk sari (Bee pollen). Pada pengambilan bee pollen secara manual dengan cara memilih kotak sarang lebah yang banyak terdapat sarang lebah kemudian diambil pollen murni yang berbentuk padatan berwarna yang terbungkus dalam propolis. Sampel yang telah terkumpul kemudian dikeringkan di bawah atap agar terhindar dari cahaya matahari langsung selama \pm 24 jam. Setelah itu sampel tersebut ditumbuk dan dihaluskan, penghalusan sampel bertujuan untuk memaksimalkan interaksi etanol (pelarut) dengan sampel (Achmad, S. 1986) bee pollen sehingga diharapkan keseluruhan metabolit sekunder dapat terekstrak, setelah sampel dihaluskan kemudian sampel yang telah halus ditimbang.

Setelah sampel halus dimaserasi dengan etanol di dalam botol gelap yang tertutup rapat agar etanol yang digunakan sebagai pelarut tidak menguap ke udara. Dalam proses maserasi dilakukan selama \pm 5 menit. Proses maserasi ini menyebabkan pelarut etanol akan menembus dinding sel sehingga dapat masuk ke rongga-rongga sel yang mengandung berbagai macam senyawa metabolit sekunder. Larutan dari maserasi tersebut disaring kemudian diuapkan (dipekatkan) pelarutnya dengan rotary evaporator, sehingga didapatkan ekstrak kasar, ekstrak fraksi etanol, dan ekstrak fraksi etil asetat, yang berwarna kuning kecoklatan.

\section{Uji Fitokimia}

Untuk mengetahui kandungan senyawa metabolit sekunder pada sampel serbuk sari (bee pollen) maka perlu dilakukan uji fitokimia dari ekstrak kasar dan dari kedua fraksi tersebut. Uji fitokimia yang dilakukan antara lain uji alkaloid, flavonoid, fenolik, saponin, steroid dan triterpenoid.

Hasil pengujian fitokimia pada ekstrak kasar, fraksi etanol dan fraksi etil asetat bee pollen ini secara kualitatif menunjukan adanya senyawa metabolit sekunder yang ditunjukkan dari hasil uji fitokimia menunjukkan bahwa di dalam ekstrak kasar terdapat jenis senyawa alkaloid dan fenolik. Pada fraksi etil asetat terdapat senyawa alkaloid dan fenolik, sedangkan pada fraksi etanol hanya terdapat senyawa metabolit sekunder alkaloid saja.

\section{Uji BSLT}

Untuk mengamati ekstrak bee pollen perlu dilakukan uji mortalitas larva udang (Brine Shrimp Lethality Test). Uji Mortalitas larva udang adalah suatu metode pegujian dengan menggunakan hewan uji yaitu larva udang Artemia salina (L.) yang dapat digunakan sebagai menentukan toksisitas suatu senyawa. Menurut (Mc Laughlin 1998) dalam pengamatan potensi bioaktivitas ini dilakukan berdasarkan nilai Lethal Concentration 50\% ( $\left.\mathrm{LC}_{50}\right)$ yaitu suatu nilai yang menunjukkan konsentrasi zat toksik yang dapat mengakibatkan kematian organisme sampai 50\%. Apabila $\mathrm{LC}_{50}<30 \mathrm{ppm}$ maka ekstrak sangat toksik dan berpotensi mengandung senyawa bioaktif antikanker. Meyer (1982) menyebutkan tingkat toksisitas suatu ekstrak :

$$
\begin{array}{ll}
\mathrm{LC}_{50} \leq 30 \mathrm{ppm} & =\text { Sangat toksik } \\
31 \mathrm{ppm} \leq \mathrm{LC}_{50} \leq 1.000 \mathrm{ppm} & =\text { Toksik } \\
\mathrm{LC}_{50}>1.000 \mathrm{ppm} & =\text { Tidak toksik }
\end{array}
$$

Berdasarkan hasil uji mortalitas larva udang dari ekstrak kasar diperoleh nilai $\mathrm{LC}_{50}$ 355,46 ppm; pada ekstrak fraksi etanol diperoleh nilai $\mathrm{LC}_{50} 249,60 \mathrm{ppm}$ dan pada ekstrak 
fraksi etil asetat diperoleh nilai $\mathrm{LC}_{50} 276,35 \mathrm{ppm}$. Nilai ini menunjukkan bahwa pada konsentrasi tersebut, ekstrak sampel mampu membunuh larva udang sampai 50\% populasi. Nilai $\mathrm{LC}_{50}$ dari uji mortalitas larva udang diperoleh dengan menggunakan Analisis Probit SAS.

Berdasarkan data di tersebut menunjukkan bahwa fraksi etanol memiliki bioaktivitas paling tinggi terhadap larva udang yang ditunjukkan dengan nilai $\mathrm{LC}_{50}$ paling kecil yaitu 249,60 ppm. Nilai ini menunjukkan bahwa pada konsentrasi 249,60 ppm fraksi etanol mampu membunuh larva udang sampai $50 \%$ populasi. Semakin kecil nilai LC 50 (Lethal Concentration 50\%) dari suatu sampel maka semakin tinggi toksisitasnya.

Tingginya aktivitas toksisitas dari fraksi etanol terhadap larva udang dibandingkan dengan ekstrak kasar dan fraksi etil asetat diperkirakan adanya kandungan senyawa alkaloid yang cukup tinggi, hal tersebut dikarenakan pada fraksi etanol senyawa alkaloid lebih aktif yaitu dalam fase yang polar (Harborne, 1987).

Pada ekstrak kasar nilai LC $_{50}$ diperoleh sebesar 355,46 ppm yang berarti bioaktivitas pada ekstrak kasar lebih rendah dibandingkan dengan fraksi etanol dan fraksi etil asetat.

Walaupun toksisitas ekstrak kasar dan fraksi etil asetat kurang dari toksisitas fraksi etanol. Namun berdasarkan studi yang dilakukan Meyer (1982), senyawa kimia dikatakan berpotensi aktif bila mempunyai nilai LC 50 kurang dari 1.000 ppm. Dengan demikian dapat dikatakan bahwa ekstrak kasar, fraksi etanol dan fraksi etil asetat berpotensi aktif karena nilai $\mathrm{LC}_{50}$ yang dihasilkan kurang dari 1.000 ppm.

\section{Uji Antioksidan dengan Metode Peredaman Radikal DPPH}

Untuk mengetahui besarnya persentase peredaman radikal DPPH (\% inhibisi) dari ekstrak serbuk sari (Bee pollen) maka dilakukan uji aktivitas antioksidan dengan metode peredaman radikal DPPH (Kumalaningsih, 2006).

Radikal DPPH larut dalam etanol dan mempunyai absorbansi yang kuat pada panjang gelombang $517 \mathrm{~nm}$ dengan warna ungu yang khas. Setelah bereaksi dengan senyawa antioksidan, DPPH tersebut akan tereduksi dan warnanya akan berubah menjadi kuning. Hasil perubahan warna dari ungu menjadi kuning sebanding dengan jumlah elektron yang ditangkap. Berikut reaksi DPPH dan antioksidan :

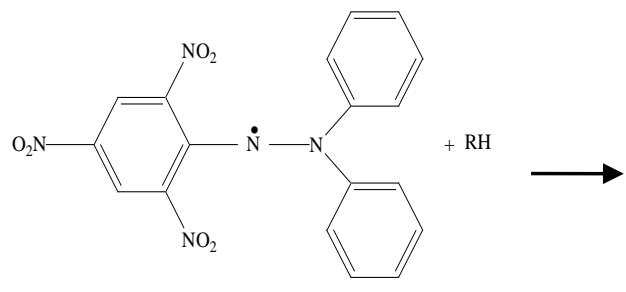

Warna ungu



Warna kuning

Setelah didapatkan panjang gelombang optimum pada $517 \mathrm{~nm}$ kemudian dilakukan pengukuran absorbansi lalu diperoleh persentase peredaman radikal DPPH dan digunakan rumus berikut untuk mengukur persen peredaman radikal DPPH (\%AA):

$$
\% \mathbf{A A}=100-\left\{\left[\left(\mathbf{A B}_{\mathbf{B}}-\mathbf{A A}_{\mathbf{A}}\right)\right] \times 100 / \mathbf{A K N}\right\}
$$

Hasil analisa dan dari perhitungan diketahui bahwa pada ekstrak kasar memiliki potensi antioksidan dengan kategori sedang dan fraksi etanol memiliki potensi antioksidan dengan kategori lemah, ini ditunjukan dari nilai $\mathrm{IC}_{50}$ yang diperoleh pada ekstrak kasar etanol 101-150 ppm dan yang diperoleh dari fraksi etanol berada pada kisaran lebih 151, yakni dengan perolehan nilai $\mathrm{IC}_{50}$ sebesar 104,84 ppm dan pada fraksi etanol dan 172,67 
ppm. Hasil fraksi etil asetat nilai $\mathrm{IC}_{50}$ yang diperoleh adalah sebesar 75,99 ppm sehingga aktivitas antioksidan yang dimiliki fraksi etil asetat dikategorikan kuat, dikarenakan nilai $\mathrm{IC}_{50}$ yang dimiliki kurang dari 50-100 ppm.

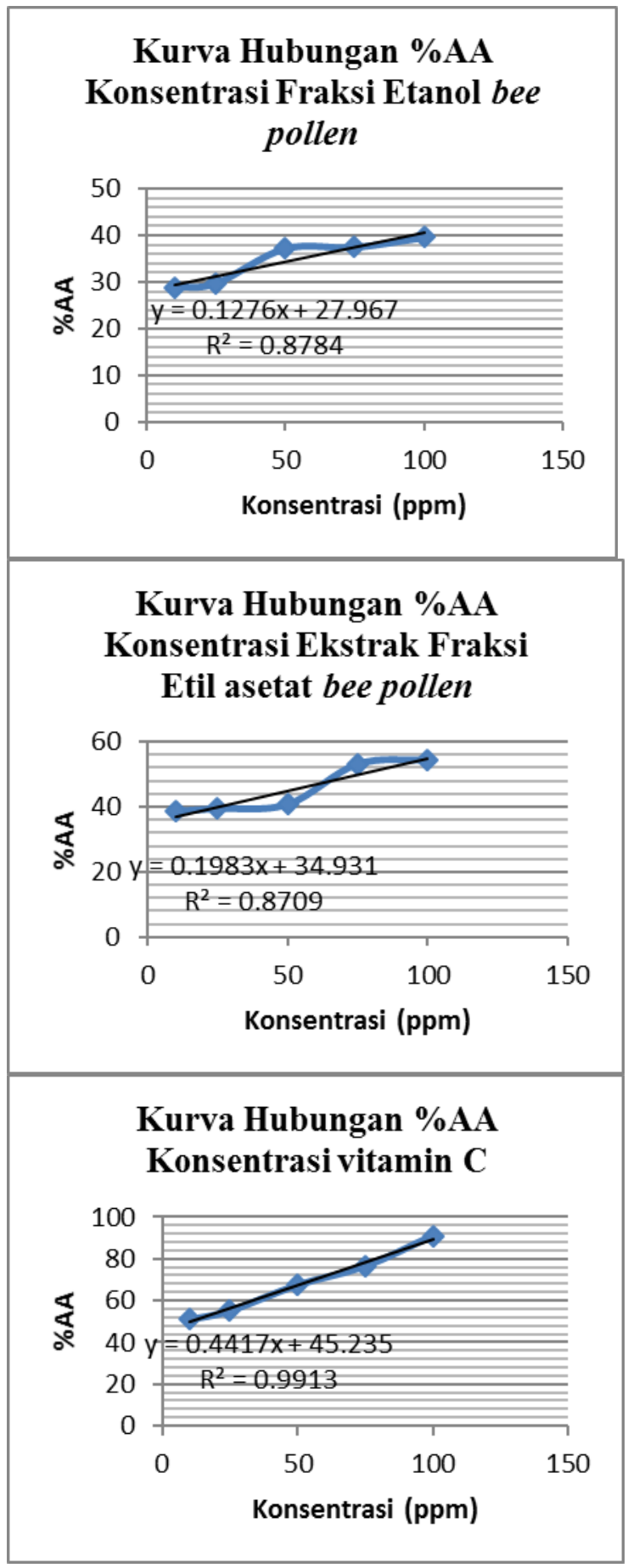



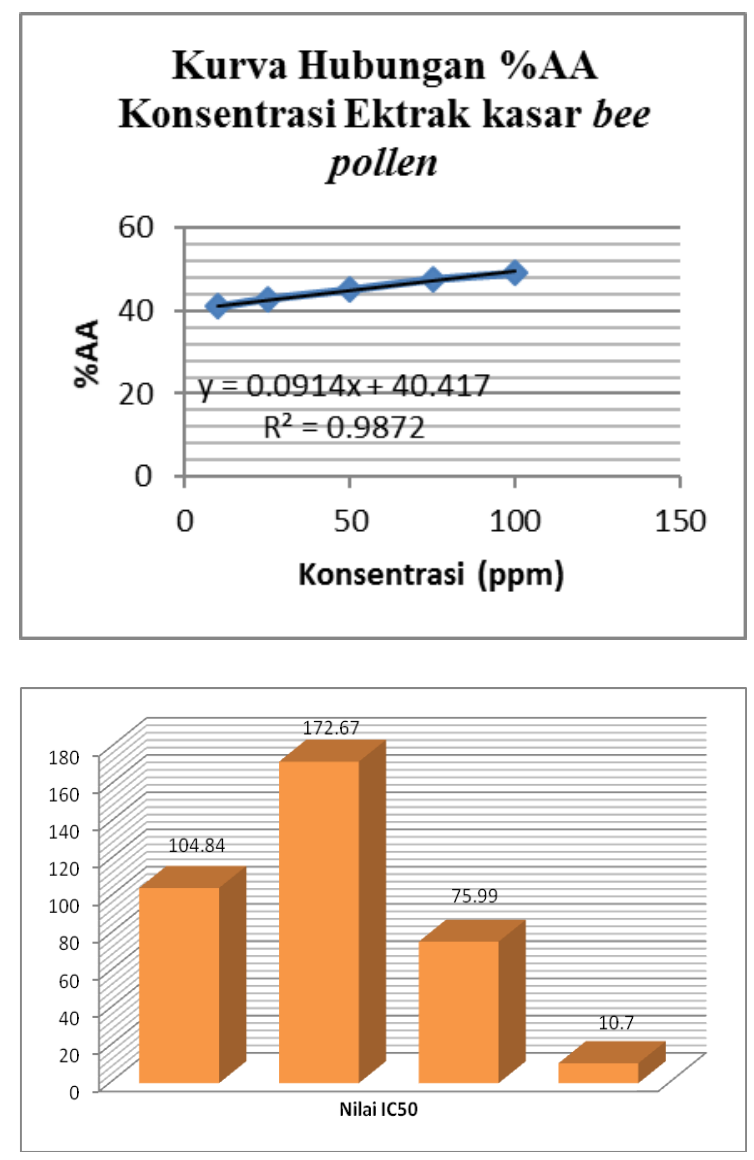

Jika hasil uji aktivitas antioksidan dihubungkan dengan nilai $\mathrm{LC}_{50}$ yang diperoleh, dapat diketahui bahwa fraksi etil asetat memiliki aktivitas antioksidan paling kuat dengan nilai $75,99 \mathrm{ppm}$ dan nilai $\mathrm{LC}_{50}$ yang diperoleh dari fraksi etil asetat adalah $276,35 \mathrm{ppm}$. Dari hasil yang diperoleh tersebut menunjukkan bahwa pada konsentrasi 75,99 ppm fraksi etil asetat mampu menangkap radikal DPPH sebesar 50\%. Sedangkan dari $\mathrm{LC}_{50}$ yang diperoleh menunjukkan bahwa pada konsentrasi 276,35 ppm fraksi etil asetat mampu membunuh larva udang sampai $50 \%$ populasi. Walaupun pada fraksi etil asetat mempunyai aktivitas antioksidan lebih besar dibandingkan dengan ekstrak kasar dan fraksi etanol, akan tetapi fraksi etil asetat tidak aman sebagai antioksidan karena nilai $\mathrm{LC}_{50}$ dibawah dari 1000 ppm atau dikategorikan bersifat toksik.

\section{Kesimpulan}

- metabolit sekunder dalam ekstrak etanol kasar yaitu, alkaloid dan fenolik, dari fraksi etil asetat terdapat alkaloid dan fenolik dan pada fraksi etanol terdapat alkaloid saja.

- Hasil uji toksisitas didapatkan nilai Lc 50 terbaik ada pada fraksi etanol yang diperoleh 249,6079 ppm dan dari uji antioksidan didapatkan nilai IC $_{50}$ ekstrak fraksi etil asetat memiliki nilai tertinggi $(75,99 \mathrm{ppm})$.

\section{Ucapan Terima Kasih}

Kepada Kementrian Pendidikan dan Kebudayaan, melalui Lembaga Penelitian Universitas Mulawarman atas pemberian pembiayaan penelitian Dikti TA-2014, pada Skim Penelitian Hibah Bersaing dengan Surat Keputusan; No, 211/UN17-16/PG/2015.

\section{DAFTAR PUSTAKA}

Achmad, S. A. 1986. Kimia Organik Bahan Alam. Jakarta: Karunika. 
Darwis, D. 2000. "Uji Kandungan Fitokimia Metabolit Sekunder: Metode Lapangan dan Laboratorium". Workshop Pengembangan Sumber Daya Manusia Dalam Bidang Kimia Organik Bahan Alam Hayati. DITJEN DIKTI DEPDIKNAS. 9-14 Oktober 2000, Padang.

Faegri, K. 1989. Text Book Pollen Analysis Edition IV . London. Alden Press.

Kumalaningsih, S. 2006. Antioksidan Alami. Jakarta : Trubus Agri Sarana.

Meyer, B. N, N.R. Ferrigni, J.E. Putman, L.B. Jacobsen, D.E. Nichol dan J.L. Melaughlin. 1982. Brine Shrimp: A Vonvenient General Bioassay for Avtive Plant Constituents. Planta Medica 45:31-34.

Sholikhah, M. 2012. Analisis Fitokimia dan Uji Daya Antimikroba Ekstrak Produk Sarang Lebah Trigona incisa Terhadap Streptococcus sobinus dan Candida albicans. Skripsi Fakultas Matematika dan Ilmu Pengetahuam Alam :UNMUL.

Syafrizal , Daniel T. dan Djumali M.2012. Kandungan metabolit sekunder madu, pollen dan propolis dari lebah kelulut (Trigona Incisa) di Kalimantan Timur. SEMINAR NASIONAL KIMIA, Samarinda 20 Oktober 2012. Himpunan Kimia Indonesia Cabang Kalimantan Timur Bekerja sama dengan Tetra Foundation Kalimantan Timur \& Dinas Pendidikan Prov. Kalimantan Timur. 